\title{
ФАКТОРЫ ВЛИЯЮЩИЕ НА КАЧЕСТВО ЖИЗНИ У БОЛЬНЫХ С ЭКСТРАПИРАМИДНЫМИ РАССТРОЙСТВАМИ
}

\author{
Матмуродов Р.Ж.* \\ Ташкентская медииинская академия, кафедры неврологии, Ташкент, Узбекистан
}

Качество жизни больных с экстрапирамидными гиперкинезами (ЭПГ) зависит от очень многих факторов которые приводят к развитию социально-экономической проблеме. Было исследовано 76 пациентов с различными формами гиперкинезов. Были проведены клинико-неврологические и нейропсихологические исследования, также нейрофизиологичесие. Результаты показали, что качество жизни пацинетов с ЭПГ зависит от клинических и не клинических факторов. Анализ выявил что основным фактором является наследственность, поэтому все пациенты и близкие родственники должны пройти гениологический и клинический осмотр. Своевременно проведенный дифференциальный диагноз и правильное лечение значительно улучшают качетсво жизни больных с ЭПГ.

Ключевые слова: экстрапирамидные гиперкинезы, болезнь Паркинсона, качество жизни.

Одной из актуальных проблем современной клинической неврологии является изучение патологии экстрапирамидной системы $[1,2,3]$. Экстрапирамидные гиперкинезы (ЭПГ) являются полиэтиологичными, имеют различные клинические проявления, а также обладают индивидуальной изменчивостью $[2,3,4,5]$. ЭПГ - относятся к наиболее распространенным неврологическим заболеваниям, приводящих к выраженным двигательным нарушениям и значительному снижению социально-бытовой адаптации и качества жизни пациентов. Они не столько угрожают жизни, сколько "разрушают" ее, значительно ограничивая функциональные возможности пациентов, приводя их к психологической и социальной изоляции $[6,7]$.

Экстрапирамидные расстройства - большая группа заболеваний различных по этиологии, патогенезу, клиническим проявлениям и морфологическим изменениям [7,8]. Трудности классификации экстрапирамидных расстройств, с одной стороны, определяются недостаточным знанием этиологии, патогенеза этих заболеваний и отсутствием, в ряде случаев, специфических маркеров болезни, а с другой - многообразием клинических проявлений, которое объясняется сложной архитектоникой и особенностями функционального взаимодействия ЭП структур. Наиболее рациональна синдромологическая классификация на основании доминирующего клинического проявления, которым могут быть, например, паркинсонизм, тремор, дистония, хорея, баллизм, атетоз, миоклония или тики $[9,10]$.

За последние 20 лет достигнуты определенные успехи в ряде научных областей, позволяющие оказывать помощь пациентам с экстрапирамидными заболеваниями на новом качественном уровне. Выявление дефектов специфических ферментов, открытие физиологических и нейромедиаторных нарушений, обнаружение генетических маркеров, успехи функциональной нейрохирургии по деструкции и стимуляции определенных ядер базальных ганглиев способствовали пониманию патогенеза ряда ЭП заболеваний [11].

Почти у всех экстрапирамидных гиперкинезов встречаются когнитивные нарушения, которые усугубляют течение болезни. А также, наблюдаются умеренные реактивные и личностные тревожные нарушения. Немоторными проявлениями при БП, нарушающими качество жизни пациентов, являются: нервно-психические нарушения: эмоциональные, когнитивные, психотические, поведенческие, нарушения сна и бодрствования; вегетативные нарушения; сенсорные нарушения и боль; утомляемость [12,13]. Одним из наиболее инвалидизирующих немоторных проявлений при болезни Паркинсона (БП) является деменция, которая встречается у 40-70\% больных [14].

Прогрессирование гиперкинезов не только зависит от клинических форм заболевания, но также зависит от очень многих факторов, которые влияют на качество жизни и инвали-

*e-mail: nevropatolog@mail.ru 
дизацию больных. Это приводит к развитию социально-экономической проблемы. В связи с этим мы перед собой поставили следующую цель: изучить основные клинические и неклинические факторы, влияющие на качество жизни пациентов с экстрапирамидными гиперкинезами.

Материал и методы исследования. Исследование было выполнено на базе 1-Республиканской клинической больницы кафедры нервных болезней Ташкентской медицинской академии. Обследовано 86 пациентов с различными экстрапирамидными расстройствами: 32 с БП, 28 с эссенциальным тремором (ЭТ), 16 с различными формами торсионной дистонии (ТД) 10 больных с лицевыми гиперкинезами (ЛК). Контрольную группу (КГ) составили 20 больных без гиперкинезов соответствующих основной группе по возрасту и полу (таб. 1).

Таблица. 1

Расспределение больных по группам

\begin{tabular}{|c|c|c|c|c|c|}
\hline & БП n-32 & ЭТ n-18 & ТД n-16 & ЛК n-10 & $\mathrm{K} \Gamma \mathrm{n}-20$ \\
\hline Пол & $\begin{array}{l}17 \text { муж. и } 15 \\
\text { жен. }\end{array}$ & $\begin{array}{l}18 \text { муж. и } 10 \\
\text { жен. }\end{array}$ & $\begin{array}{l}10 \text { муж. и } 6 \\
\text { жен. }\end{array}$ & $\begin{array}{l}6 \text { муж. и } 4 \\
\text { жен. }\end{array}$ & $\begin{array}{l}12 \text { муж. и } 8 \\
\text { жен. }\end{array}$ \\
\hline Возраст & $30-65$ & $40-60$ & $25-45$ & $23-45$ & $30-50$ \\
\hline $\begin{array}{l}\text { Средний } \\
\text { возраст }\end{array}$ & $47,8 \pm 5,1$ & $50,8 \pm 3,4$ & $35,5 \pm 3,6$ & $34,5 \pm 4,2$ & $38,5 \pm 43,6$ \\
\hline
\end{tabular}

Диагноз БП устанавливался в соответствии с критериями A.Hughes и соавт. и банка мозга Великобритании [Hughes A.J. et al., 1992]. Всем пациентам проводилось клиническое неврологическое обследование, включающее детальную оценку двигательных нарушений с использованием унифицированной шкалы оценки болезни Паркинсона (УШОБП) [Fahn. Et al., 1987]. Оценка стадии заболевания проводилась с использованием шкалы Хен и Яра [Hoehn M., Yahr V.D., 1967]. Для диагностики когнитивных нарушений в клинической практике и научных исследованиях чаще используются нейропсихологические методы исследования. Наиболее популярными и простыми для интерпретации методиками являются краткое исследование психического статуса (Mini Mental State Examination, MMSE, Folstein MF., Folstein SE., McHugh PR., 1975), батарея лобной дисфункции (Frontal Assessment Battery , FAB Dubois B., Slachevsky A., Litvan I., et al, 2000), тест рисования часов (Lezak MD., 2004). Эмоционально-личностная сфера (ЭЛС) оценивалась с помощью клинического изучения (беседа, наблюдение) и самоопросника Спилберга-Ханина (1976) и Цунга (1981). С помощью этих тестов определялся уровень реактивной тревожности и депрессии. Для оценки качества жизни в данном исследовании был использован Европейский опросник качества жизни из 5 вопросов (EuroQoL-5D). Опросник заполняется пациентом самостоятельно и включает 5 разделов, связанных со следующими аспектами жизни: подвижность, самообслуживание, активность в повседневной жизни, боль/дискомфорт, и тревога/депрессия. Каждый раздел разделен на 3 уровня в зависимости от степени выраженности проблемы - отсутствие проблемы, "определенная" проблема, "значительная" проблема.

Результаты и обсуждения. Мы детально изучали истории развития заболевания: возраст начало болезни, продолжительность болезни, особенности клиники и течения заболевания у больных с ЭПГ; проанализировали факторы, способствовавшие развитию болезни. При рандомизации больных с БП в 35\% случаев наблюдалась наследственная отягощенность по данной патологии, когда родители или близкие родственники также страдали БП. Мы наблюдали 38 летных близнецов, оба болеющих БП, а в некоторых случаях очень близкие брат-сестра, брат-брат родственники так же болели БП. У 9 пациентов была диагностирована первая стадия, у 12 пациентов вторая, у 8 пациентов третья, у 3 четвертая стадия. При изучении анамнести- 
ческих данных установлено, что средняя продолжительность болезни к началу исследова-

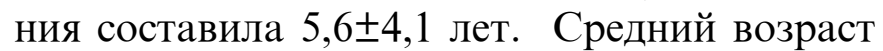
пациентов к началу заболевания был 46,8 47,3 (28-64 $\pm 5,1$ года) лет, а на момент обращения $58,9 \pm 7,0$ лет. Мы проанализировали средний возраст дебюта заболевания в зависимости от формы БП, так средний дебют болезни в об-

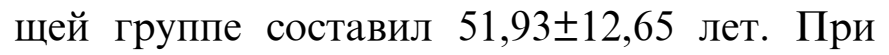
акинетико-ригидной форме средний возраст

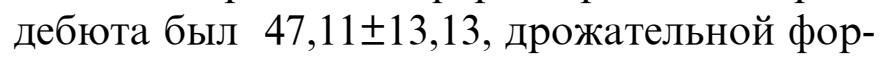

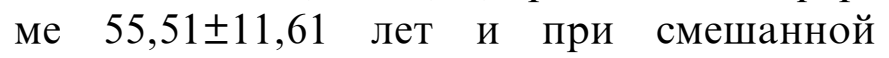
$53,01 \pm 12,48$ лет. Таким образом, можно заключить, что дрожательная форма встречается в более пожилом возрасте, а акинетико-ригидная форма начинается в более молодом возрасте. Мы анализировали выраженность моторной симптоматики по шкале УШОБП в зависимости от стадии болезни по Hoehn\&Yahr. C увеличением стадии БП увеличивалась сумма баллов по шкале УШОБП: разница в выраженности моторной симптоматики достигала статистической достоверности $(p<0,01)$ при сравнении суммы баллов по УШОБП. Результаты показывают что, эссенциальный тремор больше передается по аутосомно-доминантному типу. Заболевания больше встречался у мужчин и у них начинался раньше чем у женщин. При сравнении клинических форм ЭТ у $19(67,8 \%)$ больных встречалась классическая форма, у $5(17,8)$ больных экстрапирамидальная форма и у 4 $(14,4 \%)$ больных наблюдался мозжечковая форма. В зависимости от пола у мужчин больше встречалась классическая и экстрапирамидная форма. При сравнении средного возраста дебюта заболевания у мужчин возраст составил 45,2 22,4 года, а у женщин $58,2 \pm 3,2$. У больных торсионной дистонией больше встречалась спастическая кривошея $(87,5 \%)$. Средний возраст составил у мужчин $33,6 \pm 3,5$ лет и у женщин $38,6 \pm 2,8$ лет. Ранний дебют заболевания больше встречаля у мужчин. Из 10 больных лицевыми гиперкинезами у мужчин больше наблюдался лицевой гемиспазм $(80 \%)$ и средний возраст составил $34,5 \pm 3,6$ лет, у женщин больше встречаля лицевой параспазм.
Немоторные симптомы ЭПГ отмечались в психической, вегетативной, когнитивной и сенсорной сфере. При БП почти у всех $(87,5 \%)$ пациентов наблюдался нарушения когнитивных функций. Из них у 71,4 \% больных встречались додементные когнитивные нарушения и 29,6 \% больных деменция. При ЭТ у 25 больных $(89,2 \%)$ наблюдались когнитивные нарушения, из них 72\% додементные и 28\% деменция. У больных с торсионной дистонией в 68,75\% встречались нарушения когнитивных функций, из них 90,9 додементные и 9,1\% деменция. Тогда как у больных с лицевыми гиперкинезами почти у всех больных наблюдались додементные когнитивные нарушения. Вегетативные нарушения встречались у всех форм ЭПГ, но конечно больше наблюдались при БП - 81,25\% запор, 62,5\% ортостатическая гипотензия. Нарушения сна при БП встречаются в 1,5-3,5 раза чаще, чем в популяции пожилых людей или при других хронических заболеваниях [15]. Они затрагивают весь цикл сон-бодрствование и могут быть представлены фрагментацией сна, повышенной дневной сонливостью, нарушением поведения в фазу быстрого сна. По данным результатов нашего научного исследования выявлено, что у 25 больных $(78,13 \%)$ встречался нарушения сна. По структурам нарушения сна у $60 \%$ больных наблюдалась инсомния, 24\% больных наблюдалась парасомния и у $16 \%$ встречалась гиперсомния. А в контрольной группе эти показатели были в 4-5 раз меньше, чем в основной группе. S. Starkstein и соавт. при 4-летнем наблюдении установили, что пациенты с депрессией имеют большую вероятность развития деменции и более быстрый темп прогрессирования двигательных расстройств, чем пациенты без депрессии. В других работах было показано, что эмоциональные расстройства при БП в большей степени влияют на выраженность когнитивных нарушений, чем на их качественные характеристики [16]. Исследование депрессии и тревожности проведено у всех больных ЭПГ и в контрольной группе. Был собран психологический анамнез, чтобы исключить соматогенное происхождение тревоги и депрессии. При их наличии пациенты 
исключались из исследования. Для оценки ЭЛС были изучены уровни реактивной и личностной тревожности и депрессии. Из табли- цы 2 видно, что у всех форм ЭПГ наблюдаются немоторные проявления, которые усугубляют течение заболевания.

Немоторные симптомы у больных ЭПГ

\begin{tabular}{|l|l|l|l|l|}
\hline Немоторные симптомы & $\begin{array}{l}\text { БП } \\
\text { \% больных }\end{array}$ & $\begin{array}{l}\text { ЭТ } \\
\% \text { больных }\end{array}$ & $\begin{array}{l}\text { Торсионная } \\
\text { дистония } \\
\text { \% больных }\end{array}$ & $\begin{array}{l}\text { Лицевые } \\
\text { гиперкинезы } \\
\text { \% больных }\end{array}$ \\
\hline КН: & 87,5 & 89,2 & 68,75 & 60,0 \\
Додементные: & 71,4 & 72 & 90,9 & 100 \\
Деменция & 29,6 & 28 & 9,1 & 0 \\
\hline Вегетативные (запор) & 81,25 & 53,5 & 18,75 & 10,0 \\
\hline Нарушения сна & 78,13 & 71,4 & 62,5 & 40,0 \\
\hline Депрессия & 78,2 & 85,7 & 87,5 & 70,0 \\
\hline Тревожность & 75,0 & 82,1 & 81,2 & 80,0 \\
\hline Психозы & 18,75 & 17,8 & 25,0 & 20,0 \\
\hline Боль & 84,3 & 57,1 & 77,7 & 20,0 \\
\hline Гипосмия & 93,75 & 35,7 & 25,0 & 0 \\
\hline
\end{tabular}

Из таблицы видно, что при БП наблюдаются множество немоторных проявлений, которые не только усугубляют течение болезни, а так же влияют на качество жизни пациентов. С увеличением продолжительности болезни повышалась частота встречаемости немоторных симптомов БП, которые во многом определяли состояние больных на поздних этапах болезни. При продолжительности болезни <5 лет, деменция встречалась в 6,25\%, а при продолжительности 5-10 лет $31,25 \%$ и при $>10$ лет деменция встречался у $84,3 \%$ пациентов с БП. Частота остальных немоторных симптомов также увеличивались с продолжительностью заболевания.

Все симптомы БП оказали наибольшее влияние на компоненты опросника для определения качества жизни пациентов. Анализ опросника показал, что когда "подвижность" встречалась у 87,5\%, "боль/дискомфорт" 84,3\% и "тревога/депрессия" в 90,6\%, у них возникали "определенные" или "значительные" проблемы. Среди пациентов контрольной группы процент людей с "определенными" или "значительными" проблемами по вышеуказанным компонентам был значительно ниже $(56,25 \%, 59,3 \%$ и $62,5 \%$ соответственно, $\mathrm{p}<0,001)$. При проведении регрессионного анализа моторных и немоторных проявлений и показателей качества жизни больных с ЭПГ выявлена достоверная связь $(\mathrm{p}<0,05)$ между показателями качества жизни и баллов по шкале УШОБП (II+III), продолжительностью болезни, когнитивными нарушениями, депрессиями и тревожностями, вегетативными нарушениями, психозами, болями и расстройствами сна. Не наблюдались влияния на показатели качества жизни таких критериев как, средний возраст и возраст дебюта заболевания.

А также мы проанализировали неклинические факторы ЭПГ, которые так же влияют на качество жизни пациентов. Одним из этих факторов является поздняя обращаемость больных к специалисту. Результаты показывают что, из 32 пациентов с БП 15 больных обратились к врачу через 4-5 лет после начала болезни, в группе больных с ЭТ $21(75,0 \%)$ больной не наблюдался специалистами, а 7 $(43,75 \%)$ больных с торсионной дистонией почти не обращались к врачу. При сравнении этих показателей с показателями опросника качества жизни пациентов, выявлена достоверная связь $(\mathrm{p}<0,05)$ между показателями. Ещё одним неклиническим фактором является недифференцированная и поздняя диагнос- 
тика ЭПГ. БП всегда дифференцировалась с синдромом паркинсонизма, так как проводится дифференцированное лечение. Так противопаркинсонитическая терапия, как леводопатерапия при синдроме паркинсонизма не дает эффекта. Необходимо проведение симптоматической терапии, например, при сосудистом паркинсонизме начинать лечение сосудистыми препаратами. ЭТ клиническими проявлениями очень близка к БП, но необходима дифференцированная тактика, так как при ЭТ применяется другая лечебная тактика. Торсионная дистония, лицевые гиперкинезы проявляются разными клиническими формами и нуждаются в ботулинотоксической терапии, при некоторых вариантах это терапия не помогает. Одним из наиболее часто встречающих формы торсионной дистонии является спастическая кривошея [17]. Некоторые пациенты со спастическими кривошеями постоянно принимают миорелаксанты, как мидокалм и сирдалуд, но эффект не очень обнадёживающий. Во-вторых, они длительно принимают эти препараты, что в свою очередь приводит к развитию социально-экономической проблемы. При анализе пациентов с этими формами ЭПГ выявлено, что

\section{ЛИТЕРАТУРА}

1. Абдужамилова Р. М., Гафуров Б. Г., Алакбарова С. Ю. Анализ роли инфекционного фактора в генезе гиперкинетических синдромов // Неврология. - Ташкент, 2010. - №4. - С. 140

2. Залялова 3.А., Богданов Э.И. Экстрапирамидные гиперкинезы. Классификация, основные клинические формы, лечение: Методическое пособие для интернов, ординаторов, слушателей ФПК и врачей. Казань, 2002. $31 \mathrm{c}$.

3. Zalyalova Z., Bogdanov E., Latypova G. Therapeutic opportunities for treatment of essential tremor // Parkinsonizm \& Related Disorders. 2007. V. 13. Suppl. 2. S70.

4. Левин О. С., Московцева Ж. М. Современные подходы к диагностике и лечению тиков // Диагностика и лечение экстрапирамидных заболеваний/ Под ред. В. Н. Штока. - М., 2000. - С. 110-123.

5. Левина О.С . Сборник статей. Экстрапирамидные расстройства вчера, сегодня, завтра. - М., 2013. 328 с. 6. Шиндряева Н.Н. Качество амбулаторно-поликлинической помощи больным с экстрапирамидной патологией в нижном Новгороде. Неврологический вестник, 2010, T XLII, вып.2, С.74-78

7. Шток В. Н., Левин О. С., Федорова Н. В. Экстрапи- своевременная дифференцированная лечебная тактика положительно влияла на качество жизни пациентов (достоверная связь $(\mathrm{p}<0,05)$ между показателями).

Таким образом, на основании проведенного научного исследования можно прийти к следующим выводам:

1.Качество жизни пациентов с экстрапирамидными расстройствами зависит от клинических - возраст и дебют начало болезни, пол, продолжительность, моторные и немоторные симптомы и неклинических факторов - обращаемость, недифференцированная и поздняя диагностика, лечебная тактика и своевременная коррекция этих факторов снижает инвалидизации пациентов.

2.Экстрапирамидные гиперкинезы являются в основном наследственным, и для раннего выявления этих гиперкинезов необходимо проведение семейных клинических и генеалогических осмотров всех близких родственников специальным опросником.

3.Своевременная дифференцированная диагностика нейродегенеративных заболеваний и проведение лечебной тактики не только улучшает качество жизни, но и продлевает жизнь больных.

рамидные расстройства: Руководство для врачей. - М.: МИА, 2002. - 175 с.

8. Шабалов В.А. // Экстрапирамидные расстройства: Руководство по диагностике и лечению / Под ред. В.Н. Штока и др. М., 2002. С. 552.

9. И.А. Григорова, К.А. Лещенко, А.А. Гелетка. Этиология, патогенез, клиника, дифференциальная диагностика и лечение эссенциального тремора экспериментальная клиническая медицина. 2009. № 4. С.29.

10. Иванова И.О., Смоленская И.А. Эссенциальный тремор (клинический полиморфизм, генетика, патогенез, лечение). Экстрапирамидные расстройства: Руководство по диагностике и лечению. Под ред.В.Н. Штока, И.А. Ивановой, Смоленской, О.С. Левина. М., 2002: 273-281

11. Латыпова Г.Р., Богданов Э.И., Залялова 3.А., Забусова Л.В., Опыт оказания помощи больным с экстрапирамидными заболеваниями в Казани, Неврологический вестник 2007, №4, С.91-93.

12. Левин О.С. Не двигательные(немоторные) проявления болезни Паркинсона: диагноз и лечение. Болезнь Паркинсона и расстройства движений. Руководство для врачей под руководством С.Н. Иллариошкина., Н.Н. Яхно. - Москва, 2008. - С.94-96. 
13. Chaudhuri R.L., Yealy D.G, Shapira A.H. Non-motor symptoms of Parkinson s diseaseae // Lancet Neurol. 2006. -V.5. - P. 235-245.

14. Aarsland D., Andersen K., Larsen J.R.,et.al. Risk of dementia in Parkinson s disease: a community-based, prospektive study // Neurology. - 2001. - Vol. 56. - P. 730736.

15. Levin Ya Melatonin (melaxen) in the treatment of insomnia. Breast cancer. Man and medicine. 2005; 13 (7): 498-501
16. Нодель М.Р., Яхно Н.Н. Недвигательные нарушения при болезни Паркинсона и их влияние на качество жизни. Болезнь Паркинсона и расстройства движений. Руководство для врачей под редакцией С.Н. Иллариошкина, Н.Н. Яхно. - Москва, 2008. - С.92-94.

17. Eltahawy H.A., Saint-Cyr J., Giladi N. et al. Primary dystonia is more responsive than secondary dystonia to pallidal interventions: outcome after pallidotomy or pallidal deep brain stimulation // Neurosurgery.- 2004.- V.54. P.613-621.

\title{
XÜLASə
}

\section{EKSTRAPIRAMID POZUNTULARI OLAN XOSTOLӘRIN HəYAT KEYFIYYOTINO TəSIR EDӘN AMILLӘR}

\author{
Matmuradov R.J. \\ Daşkənd Tibb Akademiyası, nevrologiya kafedrası, Daşkənd, Özbəkistan
}

Ekstrapiramid hiperkinezləri olan xəstələrin həyat keyfiyyəti bu sosial-ekonomik problemi yaradan bir çox amillərdən asılıdır. Müxtəlif formalı hiperkinezi olan 76 pasiyent tədqiqata cəlb edilmişdir. Kliniki-nevroloji, neyropsixoloji və neyrofizioloji müayinələr aparılmışdır. Nəticələr göstərdi ki, ekstrapiramid hiperkinezləri olan pasiyentlərin həyat keyfiyyəti həm kliniki, həm də qeyri-kliniki amillərdən asılıdır. Aydın olmuşdur ki, əsas amil irsiyyətdir, bu baxımdan bütün pasiyentlər və onların yaxın qohumları genioloji və kliniki müayinədən keçməlidirlər. Vaxtında aparılan diferensial diaqnoz və düzgün müalicə ekstrapiramid hiperkinezləri olan pasiyentlərin həyat keyfiyyətini əhəmiyyətli dərəcədə yaxşııışdırır.

Açar sözlər: ekstrapiramid hiperkinezlər, Parkinson xəstəliyi, həyat keyfiyyəti.

\section{SUMMARY}

\section{INFLUENCING FACTORS ON LIFE QUALITY IN PATIENTS WITH EXTRAPYRAMIDAL DISTURBANCES}

\author{
Matmurodov R.J. \\ Tashkent Medical Academy, department of neurology, Tashkent, Uzbekistan
}

\begin{abstract}
Quality of life of patients with extrapyramidal hyperkinesia (EPH) depends on variety of different factors with leads to development of social-economic problems. 76 patients with different forms of hyperkinesia were observed. Clinical neurologic and neuropsychological examination and estimation of life quality questioner scale were conducted. Results show that quality of life of patients with EPH depends on clinical and non-clinical factors. Analysis reveal, that main factor is inheritance, so patients and all close relatives must go through genealogic and clinical examination. Timely done differential diagnosis and correctly conducted therapy gradually increase quality of life of patients with EPH.
\end{abstract}

Key words: extrapyramidal hyperkinesias, Parkinson's disease, quality of life.

Redaksiyaya daxil olub: 22.10 .2015

Çapa tövsiyə olunub: 12.11.2015

Rayçi: t.ü.f.d. Hasənov X.I. 